\title{
Trend of Changing Morphological Pattern of Adult Nephrotic Syndrome, Global and Bangladesh Perspective
}

\author{
Islam $\mathrm{SMJ}^{1}$, Alam $\mathrm{SMM}^{2}$, Islam $\mathrm{MMUI}^{3}$
}

\begin{abstract}
Nephrotic Syndrome (NS) is a clinical condition characterized by massive proteinuria, hypoalbuminemia, hypercholesterolemia, and generalized oedema. It occurs more commonly in children than in adults, and usually manifests as one of two usually idiopathic diseases: Minimal change NS (MCNS) or focal segmental glomerulosclerosis (FSGS). It has also an incidence of three new cases per 100000 each year in adults. During 70s and 80s membranous nephropathy was considered to be the prime cause of adult NS worldwide. In USA, Brazil, Singapore and South East Asian countries specially in India and Pakistan FSGS has exceeded all other causes of adult NS during last three decades. While in most of the countries of Europe, Australia, Japan, Iran IgA nephropathy has become the main cause of adult NS. Membranoproliferative glomerulonephritis (MPGN) is the predominant cause in certain countries like Russia, South Africa, Singapore etc. In some countries like UAE and Nepal MN is still found to be the main cause of adult NS. In Bangladesh only a few studies are documented which show variable predominant causes of adult NS. It is possibly due to inconsistent renal pathology facilities available in the countries and lack of dedicated renal pathologists.
\end{abstract}

\section{Introduction}

Nephrotic Syndrome (NS) is defined by massive continued losses of urinary proteins, resulting in hypoalbuminemia and oedema. These are associated with complications such as increased susceptibility to infections, thromboembolism, altered lipid and carbohydrate metabolism and losses in binding proteins in the urine ${ }^{1}$. It is a clinical condition characterized by massive proteinuria, hypoalbuminemia, hypercholesterolemia and generalized oedema ${ }^{2}$. The NS is defined by a a urinary protein level exceeding
$3.5 \mathrm{~g}$ per $1.73 \mathrm{~m}^{2}$ of body-surface area per day. At the turn of the century, clinicians distinguished a nephritic syndrome of inflammatory origin and a NS of presumed degenerative origin. Today these concepts are outmoded, but the term "NS" is clinically useful and has persisted, because heavy proteinuria, irrespective of its origin, is associated with a spectrum of clinically important sequelae, particularly sodium retention, hyperlipoproteinemia, and thromboembolic and infectious complications ${ }^{3}$.

Nephrotic Syndrome occurs more commonly in children than in adults, and usually manifests as one of two usually idiopathic diseases: Minimal change NS (MCNS) or focal segmental glomerulosclerosis (FSGS) ${ }^{4}$. It has also an incidence of three new cases per 100000 each year in adults ${ }^{5}$. Patients with NS can present to primary and secondary care with diverse symptoms that reflect the primary process or with one of the many systemic complications of the syndrome. Although NS is relatively common in renal practice but there may be delay or overlooked diagnosis as many other conditions like congestive cardiac failure, severe liver disease or allergic reactions may have similar symptoms which are more common in adults ${ }^{6}$.

Glomerular diseases in tropical countries is vastly different in epidemiology, etiology and natural history from those seen in temperate countries; and their prevalence also varies according to socio $\square$ economic conditions, race, age and indications for renal biopsy ${ }^{7}$. Over the last few years, studies have shown a changing pattern of these diseases. Previous studies showed that membranous glomerulonephritis (MGN) was the most common cause of adult NS in the United States and Europe while more recent studies have shown that the focal segmental

1. Col Sk Md Jaynul Islam, Classified Specialist in Pathology, Armed Forces Institute of Pathology, Dhaka cantonment, Dhaka 2. Brig Gen S M Mahbubul Alam, Deputy Commandant \& Adviser Specialist in Pathology, Armed Forces Institute of Pathology, Dhaka Cantonment, Dhaka 3. Dr Md Monir UI Islam, Associate Professor of Community Medicine, Gopalgonj Medical College, Gopaljonj. 
glomerulosclerosis (FSGS) is increasing significantly and it has become the most common glomerular disease in African-Americans and Hispanic populations ${ }^{8,9}$. On the basis of available articles on line this is an attempt to review the causes and morphological spectrums of NS in adult in Bangladesh and surrounding countries.

\section{Pathophysiology of proteinuria in Nephrotic Syndrome- older concept}

Passage of plasma proteins larger than $70 \mathrm{kd}$ across the glomerular basement membrane is believed to be normally restricted by a chargeselective barrier and a size-selective barrier. The charge-selective barrier is thought to be due to polyanionic glycosaminoglycans in the glomerular basement membrane, which restrict the passage of small polyanionic plasma proteins (70 to $150 \mathrm{kd}$ ), primarily albumin. It is commonly seen in minimal change disease. The size-selective barrier, which is thought to consist of pores in the glomerular basement membrane meshwork, restricts the passage of larger plasma proteins (more than $150 \mathrm{kd}$ ). It is commonly seen in membranous glomerulopathy ${ }^{10,11}$.

\section{Pathophysiology of proteinuria in Nephrotic Syndrome- Newer concept}

The mechanisms of proteinuria in primary glomerulopathies are complex and depend on all the components of the glomerular filtration barrier. In primary membranous glomerulopathy, some molecules such as megalin and phospholipase A2 receptor have been considered as being the antigens responsible for subepithelial immune complexes, which change the glomerular permeability ${ }^{12}$.

The main primary glomerulopathies that course with proteinuria are podocytopathies. The podocytopathies are characterized by changes in podocytes. These changes may be at the structural or molecular levels, and some proteins have been shown as a pivot of renal injury and proteinuria development ${ }^{13}$. Recent identification of mutations causing glomerular phenotypes, clinical biopsy reports, and experimental model systems reveal a simplified concept of glomerular diseases in which podocyte dysfunction, injury, or loss is a common and determining factor. Toxic, genetic, immune, infectious, oxidant, metabolic, hemodynamic and other mechanisms can all target the podocyte. Depending on the stage of glomerular development and associated environmental factors, podocyte dysfunction, injury, or loss can result in a broad spectrum of clinical syndromes ${ }^{14}$. According to Barisoni et al. podocyte dysfunction may have idiopathic, genetic, or reactive etiologies. The latter involves response to various insults, including mechanical stress, medications, toxins, viral infections, and as yet unidentified circulating proteins. Podocytes react to injurious stimuli in limited manner, which may include: (1) phenotype modification as foot process effacement, with no alteration in podocytes number; (2) apoptosis and loss of podocyte; (3) developmental arrest accompanied by mild proliferative activity; and (4) differentiation and re-entrance into the cell cycle with marked proliferative activity ${ }^{15}$. Some changes on the expression of nephrin, podocin, TGF- $\beta$, and slit diaphragm components as well as transcription factors and transmembrane proteins have been demonstrated in podocytopathies ${ }^{12}$.

\section{Causes of Nephrotic Syndrome}

Diabetic nephropathy is the most common cause of nephrotic proteinuria ${ }^{16}$. Several primary glomerular diseases account for the great majority of cases of the NS in persons who do not have diabetes. The important primary causes are minimal change disease, membranous glomerulopathy, focal segmental glomerulosclerosis, IgA nephropathy etc. Among the systemic diseases common causes other than diabetes mellitus are SLE (systemic lupus erythematosus), amyloidosis, multiple myeloma, HBV infection etc. The relative frequency of glomerular diseases accounting for the NS varies with age ${ }^{17}$.

\section{Minimal Change Disease}

Minimal-change disease (MCD) is the most common cause of the NS in children. It accounts for 70 to $90 \%$ of the NS in children who are younger than 10 $\mathrm{yr}$ and $50 \%$ in older children. It is also an important cause of primary NS in adults of all ages, accounting for 10 to $15 \%$ of cases ${ }^{18}$. Clinically, MCNS is characterized by highly selective proteinuria, i.e. mainly albuminuria, which generally responds well to treatment with corticosteroids. Approximately $90 \%$ of children with MCNS and up to $70 \%$ of adult patients will respond with a complete remission to a course of corticosteroids ${ }^{19}$. 
In minimal change disease (MCD) podocytes undergo a phenotypic switch from a cell with foot processes protruding from its basal surface to a cell without basal processes but which has acquired microvillus protrusions on its apical cell surface ('microvillus transformation') similar to those present in renal tubular cells. This remarkable alteration in podocyte structure is not associated with reduction in expression of key podocyte proteins such as nephrin or podocin, such as is seen in forms of focal segmental glomerulosclerosis (FSGS) although podocyte a-dystroglycan, responsible in part for adherence of the podocyte to the underlying GBM (glioblastoma multiforme) is reduced in $\mathrm{MCD}^{20,21}$. Second Northwick Park Heart Study (NPHS2) gene polymorphisms cause proteinuria in patients with minimal change disease (MCD) by depletion of dystroglycan ${ }^{22}$. It was also reported that a donor kidney from a patient with minimal-change disease functioned normally in the recipient, suggesting that a humoral factor is responsible for the disease ${ }^{23}$. Although the identity of the permeability factor has not been confirmed, Th2-derived cytokines- in particular, interleukin-13 (IL-13) and angiopoietin-like 4 - are the current main candidates ${ }^{24}$.

\section{Focal and segmental glomerulosclerosis}

Focal and segmental glomerulosclerosis(FSGS) is a pathological diagnosis highlighting the focal (some but not all glomeruli are affected) and segmental (only a part, not the entire glomerulus, is affected) nature of glomerulosclerosis. The incidence of FSGS appears to be increasing, constituting $20 \%$ and $40 \%$ of NS in children and adults, respectively ${ }^{9}$. Histologically, FSGS is characterized by increased extracellular matrix within the glomerular tuft with obliteration of the glomerular capillary lumen. These sclerotic lesions occur focally and in only some segments of glomeruli, and are typically not associated with immune complex deposition. The location of sclerotic lesions by light microscopy defines the variants of FSGS: perihilar variant (with sclerosis of the vascular pole), cellular variant (associated with hypercellularity of the capillary space), tip variant (involving the part of the glomerulus near the origin of the proximal tubule), and collapsing variant (with one or more glomeruli with global or segmental collapse) ${ }^{\mathbf{2 6}}$. It is possible that different mechanisms may play a role in the pathogenesis of each variant of FSGS ${ }^{27}$.
Key in the pathogenesis of FSGS is podocyte damage and loss. Injury to podocytes occurs by four major mechanisms: alteration of the components of the slit diaphragm or interference with its structure, dysregulation of the actin cytoskeleton, alteration of the glomerular basement membrane or its interactions with the podocyte, or alteration of the negative surface charge of the podocyte ${ }^{28}$.

FSGS involves changes in the slit membrane as well as in the cytoskeleton and cell stress ${ }^{29}$. It has been proposed that apoptosis, necrosis or loss of cellular adhesive interaction induce podocyte detachment from the GBM, playing a central role in the FSGSmediated hyperfiltration process. Modifications in the foot process cytoskeleton may lead to NS development, being podocalyxin believed to be responsible for foot process stability ${ }^{30}$. Mutations in genes coding for key podocyte and slit diaphragm proteins (Nephrin, podocin, CD2-associated protein, FAT, ZO-1, P-cadherin, a-actinin-4 etc) cause hereditary familial FSGS ${ }^{31}$. In collapsing variant, mature podocyte markers including WT1, nephrin, podocalyxin, GLEPP1, the cyclin-inhibitors p21, and p27 and foot processes are lost. In contrast, markers of immature dividing podocytes are acquired and the podocyte becomes capable of proliferating $^{32}$.

\section{Membranous glomerulopathy}

Membranous nephropathy (MN) is one of the most common causes of NS in adults, constituting up to one-third of biopsy diagnoses in some countries8. In the majority of cases, the etiologic agent is unknown, and the disorder is termed idiopathic. Secondary MN forms may account for up to one third of cases and are associated with autoimmune diseases (SLE), infections (hepatitis $B$ and $C$ ), medications (NSAID), and neoplasias (carcinomas) ${ }^{33}$.

MN is characterized by the development of immune complexes (containing mainly immunoglobulins and complement members such as C3 and C5b-9) in the subepiᄀthelial space leading to podocyte damage, causing increased production of extracellular matrix proteins and rendering the GBM thick ${ }^{34}$. In idiopathic $\mathrm{MN}$, the glomerular lesions are mainly caused by autoantibodies against a podocyte membrane protein $^{35}$, the M-type of phospholipase A2 receptor 1. A strong association with the HLA-DQA1 allele has 
been found in patients with idiopathic MN. This allele may facilitate an autoimmune response against antigenic targets such as variants ${ }^{36}$ of PLA2R1. The detection of anti-PLA2R1 autoantibodies can be useful to recognize the presence of $M N$ in patients with NS and help to diagnosis idiopathic MN in those with a renal biopsy-identified lesion of $\mathrm{MN}^{35}$.

\section{IgA Nephropathy}

$\lg A$ nephropathy is a primary glomerulopathy characterized by deposition of $\lg A$ containing immune deposits in the kidney. It causes approximately $25 \%$ of cases of idiopathic $\mathrm{NS}^{37}$. The central pathogenic mechanism is the generation of nephritogenic immune complexes, whose antigen is a poorly galactosylated form of $\lg \mathrm{A} 1$. These complexes deposit in the glomerular mesangium, eliciting a subsequent inflammatory immune response that produces tissue injury and the clinical sequelae of $\mathrm{GN}^{38}$.

\section{Diabetic glomerulopathy}

Diabetic nephropathy is the leading cause of end-stage renal disease. The major pathological findings are mesangial expansion, GBM thickening, and glomerulosclerosis ${ }^{39}$. Pathologic biopsy reports in type I diabetic glomerulosclerosis and type II diabetic glomerulosclerosis directly link reduced glomerular podocyte number to increased proteinuria $^{40,41}$. The concept of podocyte loss as a driver of the glomerulosclerotic process in diabetes is well documented. The underlying mechanisms are likely to be in part related to oxidant injury of the podocyte combined with glomerular enlargement resulting from insulin and other growth factors ${ }^{14}$.

\section{Changing etiologies of Nephrotic Syndrome}

In recent years, attention has been drawn to geographical differences in the epidemiology, aetiology and glomerular pathology of the $\mathrm{NS}^{42}$. The pattern of glomerular diseases are different in different countries and changing with time with in the same country probably due to better infection control, changes in environmental pollution, increased awareness of the disease and changes in life expectancy ${ }^{43}$. In adults, membranous nephropathy (MN) traditionally has been considered the most common cause of nephrotic syndrome (NS). During the last three decades of the 20th century, a significant development in the field of glomerular diseases was an increased frequency of focal segmental glomerulosclerosis (FSGS) among patients presenting with proteinuria and a primary glomerular disease ${ }^{44}$. According to Haas $M$ et al during the 1976 to 1979 period, the relative frequencies of membranous $(36 \%)$ and minimalchange $(23 \%)$ nephropathies and of FSGS $(15 \%)$ as causes of unexplained NS. In contrast, from 1995 to 1997, FSGS was the most common cause of this syndrome, accounting for $35 \%$ of cases compared with $33 \%$ for membranous nephropathy ${ }^{8}$. While Braden GL et al shows the increasing incidence of FSGS only in the black $(22.6 \%)$ and Hispanic $(24.6 \%)$ populations and not in white individuals in USA $^{45}$. However Swaminathan $S$ et al shows increasing incidence of FSGS among unselected patients from the community of Olmsted County. The majority of the population resided in Rochester the urban center of an otherwise rural area that has an overwhelmingly white population of predominantly Northern European extractions ${ }^{46}$. Later on during 2001 to 2011, Kraus et al. report an apparent reversal of the trend of the late 20th century regarding the relative frequencies of FSGS and MN among primary glomerular diseases in a predominantly adult and primarily African-American and Hispanic population in Chicago ${ }^{47}$.

In a large European study ranging from 1976 to 2005, Hanko JB et al show that before 1985 the predominant cause of primary glomerulopathy was MN (37\%), followed by IgA nephropathy and MCD. While after $1985 \lg A$ nephropathy became the predominant cause which reached to $43 \%$ followed by MN (26\%) and MCD (11\%). Incidence of FSGS remains between 4-6\% throughout the study duration from 1976 to 2005. The study population constitutes mostly Caucasian origin ${ }^{48}$. Another European study carried out at Moscow during 1970 to 1999 composed of 4400 study population shows MPGN $(48.9 \%)$ as the major cause of primary glomerulopathy followed by MN (13.4\%) and FSGS $(7.8 \%)^{49}$. Okpechi IG et al also found mesangiocapillary (membranoproliferative) glomerulopathy $(19 \%)$ as the commonest cause of adult idiopathic NS followed by FSGS (15.7\%) and MN (14.9\%) in a study $^{50}$ among the South African black population. Incidence of $\lg A$ nephropathy was found only in $1.7 \%$. While in Australia Briganti EM et al found IgA nephropathy $(34.1 \%)$ as the main cause of primary nephropathy followed by FSGS (16.9\%) and MN $(10.9 \%)^{51}$. A Brazilian study shows FSGS $(29.5 \%)$ as 
the predominant cause of primary glomerulopathy followed by $\mathrm{MN}(14.8 \%), \operatorname{MCD}(11.5 \%)$ and $\lg \mathrm{A}$ nephropathy $^{52}$ (11.5\%) during 1979 to 1999.

\section{Causes of adult NS in Asia}

Changing morphological patterns of NS is also observed in most of the Asian studies. A large study in China during 1979 to 2000 revealed MPGN (Membranoproliferative glomerulonephritis) (40.4\%) as the predominant cause of NS followed by $\lg \mathrm{A}$ nephropathy $(39.5 \%)$ MN (10.5\%). While another study in Northeastern region of China during 2005 to 2009 shows MCD (29.9\%) as the predominant cause of adult NS followed by $\operatorname{lgA}$ nephropathy $(28.7 \%)$. In both the studies proportion of FSGS was very less $(3.6-5.2 \%)^{53,54}$. Another study in 2009 in China revealed $\lg A$ nephropathy accounting for $>45 \%$ cases of primary glomerulopathy ${ }^{55}$. A Korean study during 1973 to 1995 found MCD (26.6\%) as the prime pattern followed by IgA nephropathy $(22.1 \%)$ and $\mathrm{MN}(11.8 \%)^{56}$. A study in Japan during 1999 also revealed IgA nephropathy $(26.8 \%)$ as the prevalent cause followed by MCD (15.7\%) and MN $(10.6 \%)^{53}$. While in UAE during1978 to 1996 , MN $(20.1 \%)$ was the commonest pattern followed by MCD (18.3\%) and FSGS $(18.3 \%)^{57}$. A Singapore based study carried out during 1976 to 2008 shows Mesangioproliferative $\mathrm{GN}$ as the predominant cause of primary glomerulopathy in 1st decade and FSGS as the predominant cause in 3 rd decade ${ }^{58}$. While a retrospective study carried out in Thailand shows significant difference between patterns of primary glomerulopathies during 1983 to 1992 and 1998 to 2005. Surprisingly during 1983 to 1992, IgM nephropathy was comprising $>60 \%$ cases of primary glomerulopathy followed by $\operatorname{lgA}$ nephropathy $(10.1 \%)$ and a very insignificant proportion of FSGS (1.4\%). In contrast during 1998 to 2005 , IgA nephropathy $(29.91 \%)$ exceeds the proportion of IgM nephropathy $(23.45 \%)$ while proportion of FSGS $(6.21 \%)$ also increased ${ }^{59}$. While in Tehran studies carried out during 80 s as well as during 1998 to 2001 found MN being the commonest cause of NS followed by IgA nephropathy and MPGN ${ }^{60,61}$.

\section{Scenario in Southeast Asia}

Trend of changing morphologic pattern of adult NS also observed in Indian subcontinent. In PGI Chandigarh during 1964 to 1980 DPGN (Diffuse Proliferative Glomerulonephritis) (36.6\%) was the commonest cause of adult NS followed by MCD
$(20.1 \%)$ and MPGN (18.6\%). During the period there were negligible proportions of FSGS (6.5\%). In the same institute another study during 2002 to 2007, there has been a fivefold increase in the frequency of FSGS $(30.6 \%)$ as a cause of NS along with a three-fold increase in MGN (24.4\%) and there has been significant decrease in DPGN (2.8\%)62. During 1971-85, at CMC Vellore India, Date et al found MCD (35.8\%) as the commonest cause of adult NS followed by FSGS (18.6\%), MPGN (13.9\%) and $\mathrm{MN}(13.6 \%)$. They got only $4.5 \% \quad \lg \mathrm{A}$ nephropathy ${ }^{63}$. While at the same institute during 1990 to 2001 Balakrishnan et al got FSGS (16.8\%) as the predominant cause of adult NS followed by MCD and $\mathrm{MN}^{64}$. While during1990 to 2008 at Hyderabad, Das $U$ et al found MCD (21.8\%) as the predominant cause of adult NS followed by FSGS $(15.2 \%)$ and $\lg A$ nephropathy $(13.8 \%)^{65}$. Reshi et al ${ }^{66}$ also got MCD as the commonest cause of NS at Kashmir during 1987 to 2000. A recent study at Kolkata, Golay et al also found FSGS (27.4\%) as the main cause of adult NS followed by MCD $(27.1 \%)$ and $\mathrm{MN}(24.6 \%)^{67}$. In Pakistan during 1998 to 2005 , a Peshwar based study shows MCD as the predominant cause of NS (40\%) in elderly patient followed by $\mathrm{MN}(20.9 \%)$ with lesser proportion of FSGS $(6.5 \%)^{68}$. While during 2007-2008, Abbas K et al found FSGS (28\%) as the main cause of NS at SIUT Karachi, followed by MCD (19.5\%) and MN $(18.5 \%)^{69}$. Afterwards Sabir $S$ et al at a naval hospital at Karachi and Mubarak et al at SIUT, also got similar findings with FSGS $(>20 \%)$ the predominant cause followed by MN (16\%) with around $5 \%$ of $\mathrm{MCD}^{70,71}$. In Sri Lanka during $1984 \mathrm{De}$ Mel WCP et al reported MN (19.4\%) as the largest group followed by membranoproliferative glomerulonephritis (16.1\%) among the patients of $\mathrm{NS}^{72}$. In Nepal Aryal $\mathrm{G}$ et $\mathrm{al}^{73}$ also got MN (42.3\%) as the leading cause of NS followed by MPGN (21.9\%) during 2001-2007.

\section{Causes of Nephrotic Syndrome in Bangladesh}

After detail search only a few published articles on adult NS from Bangladesh were found online. During 2003-2005 at Rajshahi Medical College Tarik $\mathrm{MH}$ et al carried out a study on adult NS patients and found mesangioproliferative glomerulonephritis as the commonest (40\%) morphological pattern followed by MCD (24.44\%) and membranous glomerulopathy (17.77\%). Prevalence of FSGS $(3.34 \%)$ and $\operatorname{lgA}$ nephropathy $(1.12 \%)$ were scanty 
in their study ${ }^{72}$. At the same medical college during 2008-2009 Habib MA and Badruddoza SM also got focal and segmental mesangioproliferative glomerulonephritis $(29.47 \%)$ as the most common histological pattern followed by FSGS (11.58\%) and MCD $(10.53 \%)$. In their study, incidence of IgA nephropathy was $6.85 \% 73$. While in Dhaka Medical College a study during 2011 found MN (22.12\%) as the commonest cause of NS followed by membranoproliferative glomerulonephritis (11.5\%) and IgA nephropathy $(11.5 \%)$. In their study FSGS was 7.96\%74. However Ahmed N et al at Dhaka Mitford Hospital got membranoproliferative glomerulonephritis $(40.90 \%)$ as the commonest glomerulopathy followed by FSGS $(22.72 \%)$ and MCD (18.18\%) during 2009. As per their study $\mathrm{MN}$ was only $9.09 \%$ and $\lg \mathrm{A}$ nephropathy was $4.54 \%{ }^{75}$.
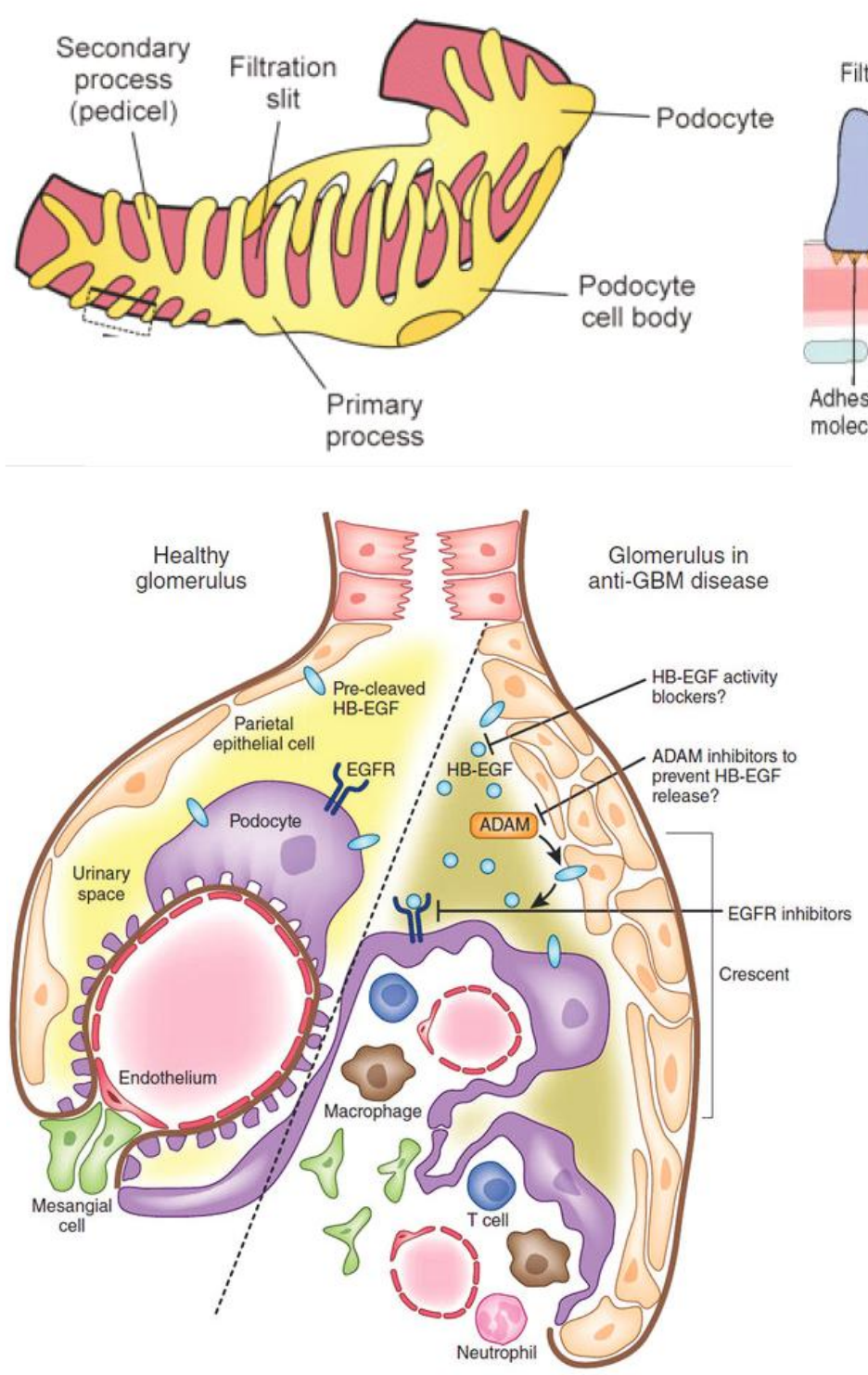

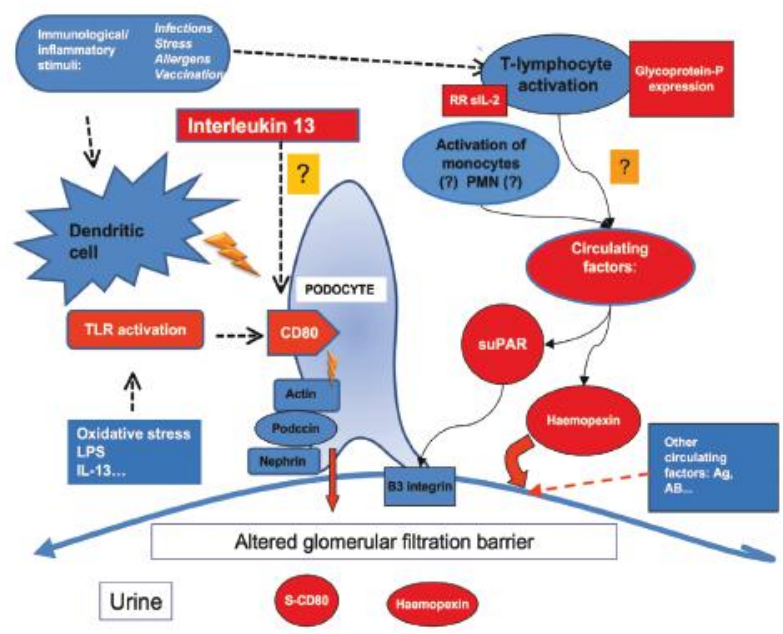

NORMAL

EPITHELIAL CELL FOOT PROCESS EFFACEMENT AND DETACHMENT

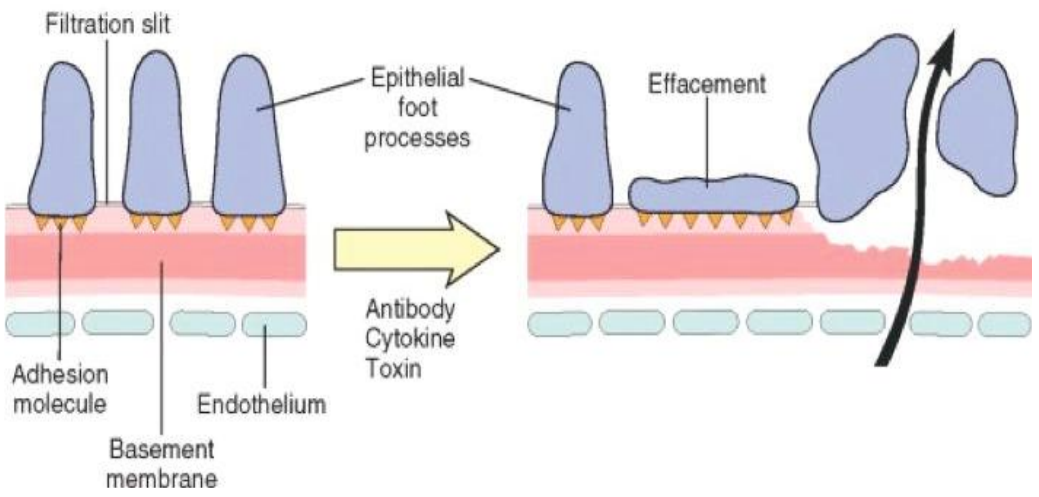

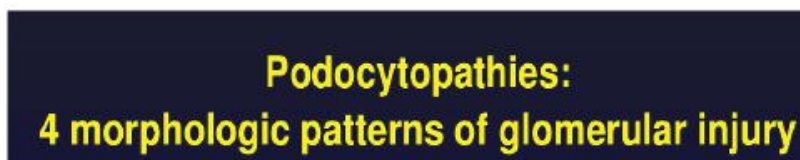

Normal

Histology

t

MCN

FSGS

DMS

Mesangial Collapse of

Sclerosis the GBM

Segmental

Sclerosis

$\downarrow$

DMS

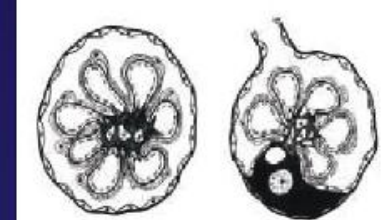

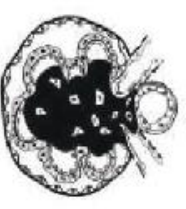

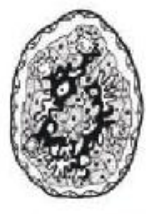



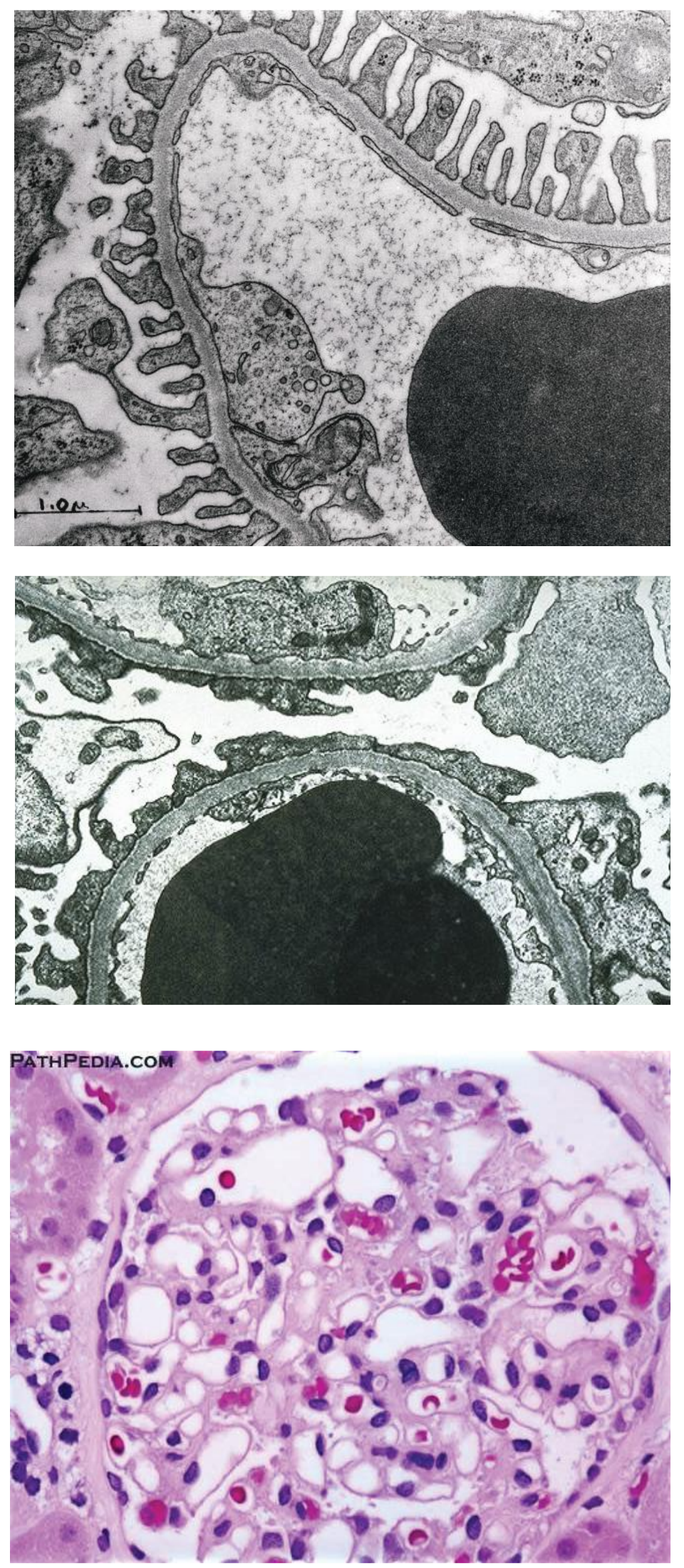

\section{Conclusion}

During 70 s and 80 s membranous nephropathy was considered to be the prime cause of adult NS. In USA, Brazil, Singapore and South East Asian countries specially in India and Pakistan FSGS has exceeded all other causes of adult NS during last three decades. While in most of the countries of Europe, Australia, Japan, Iran IgA nephropathy has become the main cause of adult NS. MPGN is the predominant cause in certain countries like Russia, South Africa, Singapore etc. In some countries like UAE and Nepal MN is still found to be the main cause of adult NS. In Bangladesh only a few studies are documented which show variable predominant causes of adult NS. It is possibly due to inconsistent renal pathology facilities available in the countries and lack of dedicated renal pathologists.

\section{References}

1. Cameron JS, Hicks JA. The origins and development of the Concept of a NS. Am J Nephrol 2002; 22:240-7.

2. Burgstein JM. NS. In: Behrman RE, Kliegman RM, Jenson HB, editors. Nelson Textbook of Pediatrics. 18th ed. Philadelphia: WB Saunders 2008; 2340-2.

3. Stephen R \& Eberhard Ritz. The NS. N Engl J Med 1998; 338(17):1202-11.

4. Eddy AA, Symons JM. NS in childhood. Lancet 2003; 362:629-39.

5. Liach F. Thromboembolic complications in the NS. Coagulation abnormalities, renal vein thrombosis and other conditions. Postgrad Med 1984; 76:111-4,116-8, 121-3.

6. Hull RP \& Goldsmith DJA. NS in adults. BMJ 2008; 336(7654):1185-9. doi: http//dx.doi.org/10.1136/bmj.39576. 709711.80 .

7. Sakhuja V, Jha V, Ghosh AK et al. Chronic renal failure in India. Nephrol Dial Transplant 1994;9:871-2.

8. Haas M, Meehan SM, Karrison TG et al. Changing etiologies of unexplained adult NS: A comparison of renal biopsy findings from 1976-1979 and 1995-1997. Am J Kidney Dis 1997; 30:621-31.

9. Kitiyakara C, Kopp JB, Eggers P. Trends in the epidemiology of focal segmental glomerulosclerosis. Semin Nephrol 2003; 23:172-82.

10. Comper WD, Glasgow EF. Charge selectivity in kidney ultrafiltration. Kidney Int 1995; 47:1242-51.

11. Shemesh O, Ross JC, Deen WM et al. Nature of the glomerular capillary injury in human membranous glomerulopathy. J Clin Invest 1986; 77:868-77. 
12. Machado JR, Rocha LP, Menezes Neves PDM, et al. An overview of molecular mechanism of NS. International Journal of Nephrology 2012 (2012), Article ID 937623, 6 pages http://dx.doi.org/10.1155/2012/937623.

13. Jennette JC and Olson JL. "The NS," in Pathology of the Kidney. Boston, Mass, USA. Little Brown 2007; 125-205.

14. Wiggins RC. The spectrum of podocytopathies: A unifying view of glomerular diseases. Kidney International 2007; 71:1205-14.

15. Barisoni L, Schnaper HW, Kopp JB. A proposed taxonomy for the podocytopathies: A reassessment of the primary nephrotic diseases. Clin J Am Soc Nephrol 2007; 2:529-42.

16. Ritz E, Stefanski A. Diabetic nephropathy in type II diabetes. Am J Kidney Dis 1996; 27:167-94.

17. Orth SR, Ritz E. The NS. N Engl J Med 1998; 338(17):1202-11.

18. Cameron JS: NS in the elderly. Semin Nephrol 1996; 16:319-29.

19. A report of the International Study of Kidney Disease in Children. The primary NS in children. Identification of patients with minimal change NS from initial response to prednisone. J Pediatr 1981; 98:561-4.

20. Barisoni L, Kriz W, Mundel P et al. The dysregulated podocyte phenotype: a novel concept in the pathogenesis of collapsing idiopathic focal segmental glomerulosclerosis and HIV-associated nephropathy. J Am Soc Nephrol 1999; 10:51-61.

21. Regele HM, Fillipovic E, Langer B et al. Glomerular expression of dystroglycans is reduced in minimal change nephrosis but not in focal segmental glomerulosclerosis. $J$ Am Soc Nephrol 2000; 11:403-12.

22. Zhu L, Yu L, Wang CD et al. Genetic effect of the NPHS2 gene variants on proteinuria in minimal change disease and immunoglobulin A nephropathy. Nephrology, 2009; 14(8):728-34.

23. Ali AA, Wilson E, Moorhead JF, et al. Minimal-change glomerular nephritis. Normal kidneys in an abnormal environment? Transplantation 1994; 58(7):849-52.

24. Chugh SS, Clement LC, Mace C. New insights into human minimal change disease: Lessons from animal models. Am J Kidney Dis 2012; 59(2):284-92.

25. Bose B and Cattran D. Glomerular diseases: FSGS. Clin J Am Soc Nephrol 2014; 9:626-632. doi: 10.2215/CJN.05810513.

26. D'Agati VD. Pathologic classification of focal segmental glomerulosclerosis. Semin Nephrol 2003; 23(2):117-34.

27. Fogo AB. Animal models of FSGS: lessons for pathogenesis and treatment. Semin Nephrol 2003; 23(2):161-71.

28. Asanuma $K$, Mundel $P$. The role of podocytes in glomerular pathobiology. Clin Exp Nephrol 2003; 7(4):255-9.

29. Schumacher V, Sch"arer K, W"uhl E, et al. Spectrum of early onset NS associated with WT1 missense mutations. Kidney International 1998; 53(6):1594-600.
30. Kerjaschki D, Sharkey DJ, Farquhar MG. Identification and characterization of podocalyxin-the major sialoprotein of the renal glomerular epithelial cell. Journal of Cell Biology 1984; 98(4):1591-6.

31. Reidy K and Frederick J. Kaske. Pathophysiology of focal segmental glomerulosclerosis. Pediatr Nephrol 2007; 22(3):350-4.

32. Shah SN, He CJ, Klotman P. Update on HIV- Associated nephropathy. Curr Opin Nephrol Hypertens 2006; 15: $450-5$.

33. Fervenza FC, Sethi S, Specks U. Idiopathic Membranous Nephropathy: Diagnosis and Treatment. Clin J Am Soc Nephrol 2008;3:905-919 doi: 10.2215/CJN. 04321007.

34. Kumagai T, Mouawad F, Takano T. Pathogenesis of common glomerular diseases-role of the podocyte cytoskeleton. Cell Health and Cytoskeleton 2012; 4:103-18.

35. Ponticelli C, Glassock RJ. Glomerular Diseases: Membranous Nephropathy- A Modern View. Clin J Am Soc Nephrol 2014; 9:609-616. doi:10.2215/CJN. 04160413.

36. Stanescu HC, Arcos-Burgos M, Medlar A et al. Risk HLA-DQA1 and PLA(2)R1 alleles in idiopathic membranous nephropathy. N Engl J Med 2011; 364:616-26.

37. Kodner C. NS in Adults: Diagnosis and Management. Am Fam Physician 2009 Nov 15; 80(10):1129-34.

38. Canetta PA, Kiryluk K, Appel GB. Glomerular Diseases: Emerging Tests and Therapies for IgA Nephropathy. Clin J Am Soc Nephrol 2014; 9:617-25. doi:10.2215/CJN.07260713.

39. Tervaert TW, Mooyaart AL, Amann K et al. Pathologic classification of diabetic nephropathy. J Am Soc Nephrol. 2010; 21(4):556-63.

40. White KE, Bilous RW, Marshall SM, et al. The European Study for the Prevention of Renal Disease in Type I diabetes (ESPRIT): podocyte number in normotensive type I diabetic patients with albuminuria. Diabetes 2002; 51:1083-9.

41. Pagtalunan ME, Miller $\mathrm{PL}$, Jumping-Eagle $\mathrm{S}$, et al. Podocyte loss and progressive glomerular injury in type II diabetes. J Clin Invest 1997; 99:342-8.

42. Anonymous. NS in the tropics. Lancet 1980; $2: 461-2$.

43. Reshi AR, Bhat MA Najar MS et al. Etiological profile of NS in Kashmir. Indian J Nephrol 2008; 18(1):9-12.

44. Dragovic D, Rosenstock JL, Wahl SJ et al. Increasing incidence of focal segmental glomerulosclerosis and an examination of demographic patterns. Clin Nephrol 2005; $63: 78-9$

45. Braden GL, Mulhern JG, O'Shea MH et al. Changing incidence of glomerular diseases in adults. Am J Kidney Dis 2000; 35:878-83.

46. Swaminathan S, Leung N, Lager DJ. Changing Incidence of Glomerular Disease in Olmsted County, Minnesota: A 30-Year Renal Biopsy Study. Clin J Am Soc Nephrol 2006; 1:483-7. doi:10.2215/CJN.00710805. 
47. Kraus MA, Punj S, Cimbaluk D et al. Resurgence of membranous nephropathy in African Americans in inner city Chicago. Clin Kidney J 2013; 6:373-8

48. Hanko JB, Mullan RN, O'Rourke DM et al. The changing pattern of adult primary glomerular disease. Nephrol Dial Transplant 2009; 24:3050-4. doi:10.1093/ ndt/gfp254.

49. Dzhanaliev BR, Varshavskii VA, Laurinavichus AA. Primary glomerulopathies: incidence, dynamics and clinical manifestations of morphological variants. Arkh Patol 2002; 64:32-5.

50. Okpechi IG, Rayner BL, Swanepoel CR. NS in Adult Black South Africans: HIV-Associated Nephropathy as the Main Culprit. J Natl Med Assoc 2010; 102:1193-7.

51. Briganti EM, Dowling J, Finlay $M$ et al. The incidence of biopsy-proven glomerulonephritis in Australia. Nephrol Dial Transplant 2001; 16:1364-7.

52. Bahiense-Oliveira M, Saldanha LB, Mota EL et al. Primary glomerular diseases in Brazil (1979-1999): Is the frequency of focal and segmental glomerulosclerosis increasing? Clin Nephrol 2004; 61:90-7.

53. Chen $\mathrm{H}$, Tang Z, Zeng $\mathrm{C}$ et al. Pathological demography of native patients in a nephrology center in China. Chin Med J (Engl) 2003; 116:1377-81.

54. Wu YQ, Wang Z, Xu HF et al. Frequency of primary glomerular disease in northeastern China. Braz J Med Bio Res Online Provisional Version. Available online July 15 , 2011. available at www.bjournal.com.br.

55. Zhou FD, Zhao MH, Zou WZ et al. The changing spectrum of primary glomerular diseases within 15 years: A survey of 3331 patients in a single Chinese centre. Nephrol Dial Transplant 2009; 24:870-6.

56. Choi IJ, Jeong HJ, Han DS, et al. An analysis of 4,514 cases of renal biopsy in Kore. Yonsei Med J 2001; 42:247-54

57. Yahya TM, Pingle A, Boobes $Y$ et al. Analysis of 490 kidney biopsies: Data from the United Arab Emirates renal diseases Registry. J Nephrol 1998; 11:148-50.

58. Woo KT, Chan CM, Chin YM et al. Global evolutionary trends of the prevalence of primary glomerulonephritis over the past three decades. Nephron Clin Pract 2010; 116:337-46.

59. Parichatikanond $P$, Chawanasuntorapoj R, Shayakul $C$ et al. An Analysis of 3,555 Cases of Renal Biopsy in Thailand. J Med Assoc Thai 2006; 89(Suppl 2):S106-11.

60. Naini AE, Harandi AA, Osarreh $S$ et al. The Relative Frequency, Clinical and Laboratory Findings of Adult Glomerulonephritidies in Tehran. JRMS 2006; 11(2):87-92.

61. Antonovych TT, Sabins SG, Broumand BB. A study of membranoprolifrative glomerulonephrotis in Iran. An Saudi Med 1999; 19(6):505-10.

62. Rathi M, Bhagat RL, Mukhopadhyay $P$ et al. Changing histologic spectrum of adult NS over five decades in north India: A single center experience. Indian J Nephrol 2014; 24:86-91. doi:10.4103/0971-4065.127892.
63. Date A, Raghavan R, John TJ et al. Renal disease in adult Indians: A clinicopathological study of 2,827 patients. Q J Med 1987; 64:729-37.

64. Balakrishnan N, John GT, Korula A et al. Spectrum of biopsy proven renal disease and changing trends at a tropical tertiary care centre 1990-2001. Indian J Nephrol 2003; 13:29-35.

65. Das U, Dakshinamurty KV, Prayaga A. Pattern of biopsy-proven renal disease in a single center of south India: 19 years experience. Indian J Nephrol 2011; 21: 250-7.

66. Reshi AR, Bhat MA, Najar MS. Etiological profile of NS in Kashmir. Indian J Nephrol 2008; 18(1):9-12.

67. Golay V, Trivedi M, Kurien AA, et al. Spectrum of NS in adults: Clinicopathological study from a single center in India. Ren Fail 2013; 35:487-91.

68. Akhter SZ, Ali A. Histological pattern of NS in elderly patients. J Ayub Med Coll Abbottabad 2008; 20(4):97-9.

69. Abbas K, Mubarak M, Kazi Jl et al. Pattern of morphology in renal biopsies of NS patients. Correlation with immunoglobulin and complement deposition and serology. J Pak Med Assoc 2009; 59(8):540-3.

70. Sabir S, Mubarak M, Haq IU et al. Pattern of biopsy proven renal diseases at PNS SHIFA, Karachi: A crosssectional survey. J Renal Inj Prev 2013; 2(4):133-7.

71. Mubarak M, Kazi JI, Naqvi R et al. Pattern of renal diseases observed in native renal biopsies in adults in a single centre in Pakistan. Nephrology (Carlton) 2011; 16 : 87-92.

72. De Mel WCP, Sheriff MHR, Balasubramanium SG et al. The histological pattern of gomerulonephritis in Sri Lankan patients with the NS. Sri Lanka Medical Association- 97th Anniversary Academic Sessions 1984; 24-5.

73. Aryal G \& Kafle RK. Hisopathological spectrum of glomerular disease in Nepal: A seven-year retrospective study. Nepal Med Coll J 2008; 10(2):126-8.

74. Tarik MH, Ekram ARMS, Haque MA et al. Renal Pathology in Adult Onset Idiopathic NS A Study of 100 Cases. TAJ 2007; 20(2):140-3.

75. Habib MA \& Badruddoza SM. Pattern of Glomerular Diseases among Adults in Rajshahi, the Northern Region of Bangladesh. Saudi J Kidney Dis Transpl 2012; 23(4): 876-80.

76. Ahmed PI, Uz-Zaman S, Jahan F et al. Pattern of primary glomerulonephritis in Dhaka Medical College Hospital, Bangladesh. Bangladesh J Medicine 2014; 25: 42-6.

77. Ahmed N, Mohosin M, Huda N. The pattern of glomerulonephritis in a study of kidney biopsy proven cases in Mitford Hospital. Bangladesh Renal Journal 2009; 28(2):29-31. 